\title{
Evidências Psicométricas da Dula Dangerous Driving Index no Brasil
}

\author{
Psychometric evidences of the Dula Dangerous Driving Index in Brazil
}

\author{
Renan Pereira Monteiro ${ }^{1}$, Emerson Diógenes de Medeiros $^{2}$, Bruna da Silva Nascimento ${ }^{3}$, \\ Talídyna Moreira de Oliveira ${ }^{4}$ e Valdiney V. Gouveia ${ }^{5}$
}

\begin{abstract}
Resumo
O presente estudo buscou explorar os parâmetros psicométricos da Dula Dangerous Driving Index (DDDI) no Brasil. Participaram 440 motoristas $\left(M_{\text {idade }}=29.6 ; D P_{\text {idade }}=10.01\right)$, divididos em dois grupos com 220 participantes cada, reagrupados para avaliar a validade concorrente da versão concisa da medida. Com o primeiro grupo verificou-se a estrutura trifatorial da DDDI, coeficientes de fidedignidade aceitáveis, dificuldade e discriminação dos itens. Selecionaram-se 15 itens com base nas análises prévias, testando sua estrutura fatorial com a segunda parte da amostra, tendo indicadores de ajuste adequados (GFI=.99; RMSEA=.03). Verificou-se a validade concorrente com base nas correlações entre a DDDI e suas subescalas com o número de multas recebidas, o envolvimento em infrações, brigas e acidentes no trânsito. Os resultados em conjunto demonstram evidências em torno da adequação psicométrica da DDDI, podendo ser uma ferramenta útil para compreender antecedentes e consequentes de ações perigosas no trânsito.
\end{abstract}

Palavras-chave: psicologia do trânsito, direção perigosa, medida, validade, precisão

\begin{abstract}
This study aimed to explore the psychometric parameters of the Dula Dangerous Driving Index (DDDI) in Brazil. Four hundred and forty drivers $\left(M_{a g e}=29.6 ; S D_{a g e}=10.01\right)$ divided into two groups with 220 participants each, regrouped to evaluate the concurrent validity of the concise version of the measure. With the first group, the DDDI three-factor structure was verified, presenting acceptable reliability, difficulty and discrimination of the items. Based on previous analysis, 15 items were selected, testing their factor structure with the second group of participants, observing acceptable fit indexes (GFI=.99; RMSEA=.03). The concurrent validity was verified based on correlations between the DDDI, its subscales and the number of fines received by the drivers, involvement in infractions, traffic accidents and fights. The results provided evidences supporting the DDDI adequacy, which can be a useful tool to understand the antecedents and consequences of risk actions in traffic.
\end{abstract}

Keywords: traffic psychology, dangerous driving, measure, validity, reliability

\footnotetext{
${ }^{1}$ Doutor em Psicologia Social. Professor da Universidade Federal de Mato Grosso. Campus de Cuiabá, Departamento de Psicologia. Av. Fernando Corrêa da Costa, 2367 - Boa Esperança, Cuiabá - MT, 78060-900. Tel: +55(86)3323-6335. Email: renanpmonteiro@gmail.com

${ }^{2}$ Doutor em Psicologia Social. Professor Adjunto da Universidade Federal do Piauí, Brasil.

${ }^{3}$ Doutoranda em Psicologia pela University of Bath, Reino Unido.

${ }^{4}$ Estudante de Graduação em Psicologia pela Universidade Federal do Piauí, Brasil.

${ }^{5}$ Doutor em Psicologia Social. Professor Titular da Universidade Federal da Paraíba, Brasil.
} 


\section{Introdução}

Acidentes de trânsito causam aproximadamente 1,2 milhão de mortes por ano (WHO, 2015). No Brasil a mortalidade por acidentes, de acordo com a WHO, é de 23,4 óbitos a cada 100.000 habitantes, levando o país a $57^{\mathrm{a}}$ posição entre 180 países analisados, sendo o terceiro nas Américas. Especificamente, o DATASUS (http://tabnet.datasus.gov.br/cgi/deftohtm.e xe?sim/cnv/ext10uf.def) informa que dos 156.942 óbitos por causas externas, no Brasil em 2014, 44.823 foram causados por acidentes de trânsito. É perceptível a magnitude do problema no Brasil, constituindo grave questão de saúde pública.

Nos últimos anos, leis mais rigorosas têm sido propostas no Brasil objetivando reduzir o número de acidentes, a exemplo da Lei 11.705 aprovada em 2008, que reduz a tolerância no nível de álcool no sangue de quem dirige. Observa-se maior fiscalização e controle sobre a segurança veicular, contudo, o número de mortes e lesões causadas por acidentes não diminui (Bacchieri \& Barros, 2011). Ressalta-se que o fator humano é o principal responsável pelos acidentes com veículos automotores (Wit, Souza, \& Cruz, 2016), sendo que a identificação de grupos de risco (por exemplo, pessoas com elevado nível de ansiedade, agressividade ou busca de sensações) possibilita delinear intervenções objetivando reduzir o número de colisões. Portanto, além de ações punitivas e de fiscalização, é fundamental traçar o perfil de motorista mais predisposto para envolver-se em acidentes de trânsito. A propósito, é possível observar em diferentes contextos (por exemplo, Brasil e Portugal) que é fundamental passar por uma avaliação psicológica durante o processo de obtenção da habilitação, orientando psicólogos na tomada de decisão sobre a aptidão, ou não, que os indivíduos têm para condução (Alchieri \& Stroher, 2003; Ferreira, Maurício, \& Simões, 2013).

Uma das diferenças individuais preditoras do envolvimento em acidentes de trânsito é a direção perigosa (Richer \& Bergeron, 2012; Wu, AgueroValverde, \& Jovanis, 2014), definida como ações ao volante que podem colocar em risco as demais pessoas (Iliescu \& Sârbescu, 2013). Especificamente, a direção perigosa envolve atos intencionais de agressão física, verbal ou psicológica contra outros motoristas, pedestres ou passageiros; sentir emoções negativas enquanto dirige (frustração, raiva, ira); e correr riscos ao volante, sem a intenção de causar dano aos demais (excesso de velocidade, mudança constante de faixa; Dula \& Geller, 2003).

Estimar tais aspectos é um passo importante para se pensar em estratégias para promover um trânsito seguro. Contar com uma forma de quantificar a direção de risco possibilita conhecer em que medida os motoristas são propensos a se envolverem em colisões e que variáveis psicossociais podem contribuir para o entendimento de ações perigosas no trânsito. A propósito, é possível encontrar a Dula Dangerous Driving Index (DDDI), um instrumento proposto por Dula e Ballard (2003) cobrindo dimensões como direção agressiva, direção de risco e cognições/emoções negativas ao dirigir, que, conjuntamente, formam a direção perigosa. Portanto, considerando o papel preditor da direção perigosa para o envolvimento em acidentes, aliado aos dados alarmantes referentes ao trânsito brasileiro, é pertinente proceder com a adaptação de instrumentos avaliativos para o Brasil. A seguir, a DDDI será descrita em maiores detalhes.

\section{Dula Dangerous Driving Index}

Elaborada por Dula e Ballard (2003) a DDDI é um instrumento, de autorrelato, que avalia a propensão das pessoas para dirigir perigosamente. A escala mensura a frequência com que as pessoas agem agressivamente no trânsito, em que medida elas experimentam emoções e cognições negativas ao dirigir e o quanto elas se arriscam no trânsito. $\mathrm{Na}$ construção da escala, Dula e Ballard realizaram um estudo piloto com 23 universitários, aplicando a versão preliminar da medida composta por 96 itens, criados com base em estudos prévios e testemunhos. Os participantes avaliaram cada item numa escala de 5 pontos (1=Nem um pouco agressivo; 5=Extremamente agressivo), indicando o quanto cada um estava associado a direção perigosa. Baseado nestas avaliações, os autores calcularam as médias para cada item, separando-os em três grupos com 32 itens cada, escolhendo o grupo de itens com médias superiores, assegurando a validade aparente. Não obstante, estes autores eliminaram um item por julgá-lo irrelevante, 
sendo a versão resultante da DDDI formada por 31 itens.

Baseado no conteúdo dos itens e análise de juízes, os 31 itens foram reduzidos para 28, excluindo-se um item com elevada média na etapa anterior, outro por ser demasiado subjetivo ("Eu sou um motorista agressivo") e por fim, excluiu-se o item "Eu tenho algum tipo de arma no meu carro/caminhão" por não estar diretamente relacionado à atividade de dirigir. Os 28 itens restantes foram divididos em três subescalas: Direção Agressiva, Emoções/Cognições Negativas ao Dirigir e Direção de Risco. Esta versão foi aplicada a 119 universitários, apresentando indicadores de consistência interna aceitáveis $(\alpha=.83$ a .85$)$, além da pontuação total da DDDI e suas subescalas se correlacionarem positivamente, por exemplo, com agressão física, verbal e raiva. Dula e Ballard (2003) verificaram, ainda, que a DDDI e seus fatores específicos se correlacionaram positivamente com o número de multas recebidas e que a pontuação total da escala e a subescala Direção de Risco se correlacionaram positivamente com o envolvimento em acidentes.

A DDDI tem sido frequentemente utilizada por pesquisadores para operacionalizar a direção perigosa, verificando o seu papel para a compreensão do envolvimento em acidentes de trânsito (Wu et al., 2014). Os pesquisadores também utilizam os escores da DDDI e suas subescalas como variável critério em estudos que objetivam conhecer fatores explicativos da direção perigosa. Por exemplo, estudos tem verificado que o estresse predisse positivamente Emoções/Cognições Negativas, Direção Agressiva, Direção de Risco e a pontuação total da DDDI (Ge et al., 2014) e que pessoas com elevados níveis de ansiedade apresentam escores mais elevados nessas últimas três variáveis da direção perigosa (Dula, Adams, Miesner, \& Leonard, 2010). Estes achados apontam que pessoas ansiosas e estressadas podem ser um grupo de risco para envolver-se em acidentes, cabendo pensar em ações interventivas para tais grupos, proporcionando o gerenciamento das emoções e comportamento seguro no trânsito (Dula et al., 2010; Ge et al., 2014).

A utilidade da DDDI tem levado pesquisadores a adaptá-la para diferentes contextos. Em sua adaptação para a Romênia
(Iliescu \& Sârbescu, 2013), a DDDI apresentou evidências com alfas aceitáveis $(\alpha>$.70), além de validade incremental na predição de infrações no trânsito, controlando o sexo e idade dos motoristas. Entretanto, ao testar a estrutura fatorial, Iliescu e Sârbescu (2013) não encontraram suporte para um modelo hierárquico, com um fator geral e três de segunda ordem (CFI=.79).

No contexto francês, Richer e Bergeron (2012) reuniram evidências adicionais em torno da DDDI. Estes autores verificaram alfas acima de 0,70 , indicadores de ajuste do modelo aos dados que apoiam a estrutura trifatorial (CFI=.92; TLI=.91; RMSEA=.05) e evidências de validade concorrente, a exemplo de correlações positivas com infrações e colisões. Adaptações desta medida para a China $(\mathrm{Qu}, \mathrm{Ge}$, Jiang, Du, \& Zhang, 2014) e Bélgica (Willemsen, Dula, Declercq, \& Verhaeghe, 2008) tem dado suporte para uma estrutura de quatro fatores, formada pelas três dimensões expostas anteriormente e uma composta por dois itens que compõem um fator chamado Dirigir Embriagado. Contudo, pode-se interpretar que dirigir sob efeito de substâncias é um comportamento de risco ao volante.

A potencial aplicabilidade da DDDI, o seu crescente emprego nas pesquisas para a operacionalização da direção perigosa, os estudos que têm adaptado esta medida para diferentes contextos e os dados sobre o trânsito brasileiro ensejaram o desenvolvimento do presente estudo. Logo, o propósito deste artigo é conhecer evidências psicométricas da Dula Dangerous Driving Index no contexto brasileiro. Especificamente, checar evidências em torno da dimensionalidade da escala, da discriminação e dificuldade de seus itens, além de avaliar a sua fidedignidade e validade concorrente.

\section{Método}

\section{Participantes}

Participaram 440 pessoas da população geral, com idades variando entre 18 a 67 anos $(M=29.6$; $D P=10.01)$. A maioria da amostra foi composta por mulheres $(61.0 \%)$, pessoas solteiras $(64.0 \%)$, com ensino superior incompleto (39.9\%) e que se autodeclararam de classe média $(62.1 \%)$, sendo 
que $88.5 \%$ afirmaram ter Carteira Nacional de Habilitação, com tempo de habilitado variando entre 1 e 492 meses $(M=80.9 ; D P=81.52)$.

\section{Instrumentos}

A Dula Dangerous Driving Index (DDDI; Dula \& Ballard, 2003) é formada por 28 itens, distribuídos em três fatores. Os participantes devem indicar com que frequência ( $1=N u n c a$; $5=$ Sempre $)$ apresentam certos comportamentos no trânsito, como, por exemplo, "Insulto verbalmente os motoristas que me irritam" (Direção Agressiva), "Costuro o trânsito lento, mudando constantemente de faixa" (Direção de Risco) e "Quando fico preso em um engarrafamento fico muito irritado" (Emoções/Cognições Negativas).

Dois psicólogos bilíngues traduziram os itens da DDDI do inglês para o português. Um terceiro psicólogo sintetizou as versões e retraduziu os itens do português para o inglês, observando-se equivalência com a versão original da medida. A versão preliminar do instrumento foi aplicada em 10 motoristas para estimar em que medida as instruções, itens e escala de resposta eram compreensíveis. Desta etapa não se demandou qualquer alteração. Os leitores interessados na versão traduzida da escala podem solicitá-la a um dos autores do presente estudo.

Nesta ocasião foram selecionadas 17 infrações listadas no Código de Trânsito Brasileiro para compor a Escala de Infrações de Trânsito. Este instrumento foi elaborado com o propósito de se verificar em que medida a DDDI e seus fatores se relacionam com infrações corriqueiras de trânsito. Para responder o instrumento, os participantes deveriam indicar com que frequência $(1=$ Nunca; $5=$ Sempre) nos últimos 12 meses eles apresentaram condutas como "Avançar o sinal vermelho do semáforo" (infração gravíssima), "Dirigir sem usar o cinto de segurança" (infração grave), "Estacionar na contramão" (infração média), "Usar a buzina de forma prolongada e sucessiva por qualquer motivo" (infração leve). Esta escala apresentou coeficiente alfa aceitável $(\alpha=75)$, considerando a amostra aqui utilizada.

Por fim, os participantes responderam a um conjunto de questões demográficas. Nesta parte existiam questões referentes à caracterização da amostra (como idade, sexo, estado civil, escolaridade) e questões específicas sobre o comportamento das pessoas no trânsito, como a frequência de envolvimento em acidentes, o número de multas recebidas e o número de brigas de trânsito no qual o partícipe se envolveu.

\section{Procedimento}

Os dados foram coletados por meio de questionário online, sendo o link divulgado em redes sociais, utilizando-se do procedimento bola de neve. No caso, foi solicitada a colaboração das pessoas para que participassem do estudo e que elas compartilhassem o link da pesquisa entre os seus contatos. Enfatizou-se que o pré-requisito para compor a amostra era saber dirigir. $\mathrm{Na}$ primeira página do questionário eram apresentadas informações que versavam sobre os objetivos do estudo, bem como informações que asseguravam o caráter anônimo e voluntário da participação, que para ser iniciada demandava-se do participante que clicasse em uma opção referente ao consentimento livre e esclarecido.

\section{Análise de Dados}

Os dados foram analisados por meio dos softwares SPSS v.23, Factor v.10.5 (LorenzoSeva \& Ferrando, 2006), Mplus v.7 (Muthén \& Muthén, 2012) e R ( $R$ Development Core Team, 2017). Com o primeiro foram realizadas estatísticas descritivas e análise de correlação de Pearson. Com o segundo foi possível avaliar o melhor número de fatores a serem retidos para a DDDI, utilizando-se como critérios a Análise Paralela (Horn, 1965) com permutação aleatória dos dados (Timmerman \& Lorenzo-Seva, 2011) e Método Hull (Lorenzo-Seva, Timmerman, \& Kiers, 2011). O Mplus foi utilizado para se conhecer a estrutura fatorial da medida, utilizando-se da modelagem por equações estruturais exploratória (Exploratory Structural Equation Modeling, ESEM; Muthén \& Muthén, 2012), com método de estimação Weighted Least Squares Mean-and-variance Adjusted (WLSMV; Muthén \& Muthén, 2012), além de rodar Análises Fatoriais Confirmatórias (AFC). Por fim, por meio do pacote MIRT (Chalmers, 2012) foram calculadas as análises de TRI, avaliando a dificuldade e discriminação, por meio do Modelo de Resposta Graduada (Samejima, 1969).

No que tange a ESEM e AFC foram adotados os seguintes índices de ajuste: Comparative Fit 
Index (CFI), Tucker-Lewis Index (TLI) e Root Mean-Square Error of Approximation (RMSEA). Para um modelo ajustado, os valores de CFI e TLI devem ser superiores a .90 , preferencialmente acima de .95 (Kline, 2016), e o RMSEA abaixo de .08 (Brown, 2006; Kline, 2016).

\section{Resultados}

A amostra foi dividida aleatoriamente para a realização da ESEM e análise pela Teoria de Resposta ao Item $\left(N_{l}=220\right)$ e para Análise Fatorial Confirmatória $\left(N_{2}=220\right)$. Para as análises de validade concorrente, foram considerados todos os participantes $\left(N_{T}=440\right)$. A seguir os resultados são expostos em tópicos conforme as análises empregadas.

\section{ESEM - Modelagem por equações estruturais exploratória}

Inicialmente, demandou-se conhecer a dimensionalidade da DDDI, utilizando-se das seguintes técnicas de retenção de fatores, a análise paralela (Timmerman \& Lorenzo-Seva, 2011) e o método Hull (Lorenzo-Seva, Timmerman, \& Kiers, 2011), que apontaram a pertinência de extração de três e dois fatores, respectivamente. Deste modo, foram executadas duas ESEM, com estimador WLSMV, tendo em conta as estruturas indicadas. A estrutura bifatorial [RMSEA $=.059$ (IC90\%=.051-.067); CFI $=.912$ e TLI=.897] foi preterida em função do ajuste superior do modelo trifatorial [RMSEA $=.048 \quad($ IC90\%=.038-.057); $\mathrm{CFI}=.947$ e $\mathrm{TLI}=.933]$. Ressalta-se que para o refinamento da medida, a retenção do item se dava com carga fatorial mínima $.30 \mathrm{em}$ seu fator teoricamente esperado (ver Quadro 1).

O primeiro fator, Direção Agressiva (DA), reuniu inicialmente oito itens, entretanto os itens 22 (Eu sinto que motoristas passivos deveriam aprender a como dirigir ou então ficar em casa) e 26 (Sinto que posso perder a calma se tiver que confrontar outro motorista) foram eliminados por não avaliarem o fator em questão. Assim, as cargas fatoriais dos seis itens restantes variaram entre .46 (Item 16. Quando alguém me corta no trânsito, sinto que eu deveria puni-lo) a .89 [Item 5. Faço gestos rudes (por exemplo, "dou o dedo", ou grito palavrões) aos outros motoristas que me chateiam]. $\mathrm{O}$ fator apresentou aceitável fidedignidade, avaliada pelo Ômega de McDonald $(\omega=.85)$ e Confiabilidade Composta $(\mathrm{CC}=.81)$.

$\mathrm{O}$ segundo fator, Emoções/Cognições Negativas ao Dirigir (ECN), foi composto inicialmente por dez itens, entretanto, os itens 4 (Pisco o farol do carro quando me irrito com outro motorista), 14 (Costuro o trânsito lento, mudando constantemente de faixa) e 21 (Sinto que é meu direito andar o mais rápido possível para chegar onde eu preciso) foram excluídos por não pertencerem teoricamente/semanticamente a tal dimensão. Os sete itens restantes apresentaram saturações entre .41 (Item 1. Dirijo quando estou zangado ou chateado) a .87 (Item 17. Fico impaciente e/ou chateado quando dirijo e estou atrasado), observando-se coeficientes de confiabilidade adequados $(\omega=.75 ; \mathrm{CC}=.82)$.

Por fim, o terceiro fator, identificado como Direção de Risco (DR), reuniu inicialmente dez itens. Contudo, o item 9 (Alinho o meu carro com o dos outros condutores no semáforo, buscando ser o primeiro a arrancar) foi excluído por apresentar saturação abaixo do ponto de corte estabelecido. Os demais itens apresentaram cargas fatoriais que variaram entre .35 (Item 28. Eu sinto que a maioria das regras do código de trânsito poderia ser considerada como sugestões) a 0,76 (Item 25. Sou capaz de dirigir quando estou bêbado). $\mathrm{O}$ fator apresentou indicadores de precisão aceitáveis $(\omega=.86 ; \mathrm{CC}=.81)$.

\section{Análise pela Teoria de Resposta ao Item e versão reduzida da DDDI}

Em seguida avaliou-se, tendo em conta a mesma amostra $\left(\mathrm{N}_{1}\right)$, por meio do Modelo de Resposta Graduada (Samejima, 1969) os parâmetros de dificuldade e discriminação dos 22 itens da DDDI. Ademais, tendo o objetivo de se propor uma versão reduzida da DDDI, foram escolhidos, a partir da discriminação e informação, os 5 melhores itens de cada uma das três dimensões, para serem analisados a partir de uma Análise Fatorial Confirmatória, com estimador WLSMV. Os resultados podem ser observados no Quadro 2.

No que tange à discriminação dos itens do fator Direção Agressiva, observou-se um valor médio de $1.84(D P=1.03)$, variando de .93 (Item 11) a 3.40 (Item 5). O item mais facilmente endossado em todos os limiares $\left(b_{1-} b_{4}\right)$ foi o 6 , ao 
Quadro 1. Estrutura fatorial da Dula Dangerous Driving Index

\begin{tabular}{|c|c|c|c|}
\hline \multirow{2}{*}{ Itens Resumidos } & \multicolumn{3}{|c|}{ Cargas Fatoriais } \\
\hline & DA & $\mathrm{ECN}$ & DR \\
\hline 5. Fazer gestos rudes aos motoristas que me irritam & $.89 *$ & .01 & .02 \\
\hline 6. Insultar verbalmente os motoristas que me irritam & $.84 *$ & .01 & -.03 \\
\hline 8. Deveria colar na traseira dos motoristas que me irritam & $.66 *$ & -.10 & .16 \\
\hline $\begin{array}{l}\text { 11. Se um motorista é agressivo comigo, sinto que eu tenho o direito de dar o troco de } \\
\text { alguma forma }\end{array}$ & $.51 *$ & .06 & .12 \\
\hline 7. Usar veículo para bloquear motoristas que colam na traseira do meu carro & $.47 *$ & .22 & -.07 \\
\hline 16. Quando alguém me corta no trânsito, sinto que eu deveria puni-lo & $.46 *$ & .15 & .19 \\
\hline 26. Sente que pode perder a calma se tiver que confrontar outro motorista & .30 & .23 & .14 \\
\hline $\begin{array}{l}\text { 22. Sente que motoristas passivos deveriam aprender a como dirigir ou então ficar em } \\
\text { casa }\end{array}$ & .29 & .28 & .15 \\
\hline 17. Ficar impaciente e/ou chateado quando dirige e está atrasado & -.06 & $.87 *$ & .01 \\
\hline 19. Ficar irritado quando um carro à frente reduz a velocidade sem razão & .01 & $.66 *$ & .12 \\
\hline 12. Quando fica preso em um engarrafamento fica muito irritado & -.10 & $.63 *$ & .10 \\
\hline 3. Considerar que as ações dos outros motoristas são inadequadas ou "estúpidas" & -.01 & $.61 *$ & -.16 \\
\hline 2. Perder a calma quando está dirigindo & .22 & $.60 *$ & -.14 \\
\hline 18. Passageiros que me acompanham costumam dizer-me para me acalmar & .07 & $.54 *$ & .13 \\
\hline 1. Dirige quando está zangado ou chateado & .04 & $.41 *$ & .13 \\
\hline 14. Costurar trânsito lento, mudando constantemente de faixa. & -.01 & .39 & .31 \\
\hline 21. Sente que tem direito de andar o mais rápido possível para chegar onde precisa & .04 & .38 & .30 \\
\hline 4. Piscar o farol do carro quando se irrita com outro motorista & .29 & .34 & -.03 \\
\hline 9. Alinhar carro com de outros condutores no semáforo, para ser o primeiro a arrancar & .12 & .25 & .28 \\
\hline 25. Capaz de dirigir quando está bêbado & .14 & .01 & $.76^{*}$ \\
\hline 23. Dirigir pelo acostamento ou canteiro central para fugir de engarrafamento & .09 & -.01 & $.70 *$ \\
\hline 27. Considero que sou uma pessoa que se arrisca & -.1 & .18 & $.67 *$ \\
\hline 15. Capaz de dirigir se estiver levemente intoxicado ou tonto & .05 & -.02 & $.62 *$ \\
\hline 20. Cruzar dupla faixa contínua amarela para ultrapassar veículo lento & .01 & .20 & $.62 *$ \\
\hline $\begin{array}{l}\text { 13. Acelerar para passar em cruzamento férreo antes de um trem em movimento lento } \\
\text { chegar }\end{array}$ & .19 & -.02 & $.48 *$ \\
\hline $\begin{array}{l}\text { 24. Ultrapassar em estrada de duplo sentido e por pouco não bater nos carros que vêm em } \\
\text { sentido oposto }\end{array}$ & -.02 & -.17 & $.45^{*}$ \\
\hline 10. Cometer infração para ultrapassar um veículo que vai muito devagar & .17 & .08 & $.45^{*}$ \\
\hline 28. Sentir que regras do código de trânsito poderiam ser consideradas sugestões & -.04 & .12 & $.35 *$ \\
\hline Numero de itens & 6 & 7 & 9 \\
\hline Ômega de McDonald & .85 & .75 & .86 \\
\hline Confiabilidade composta & .81 & .82 & .81 \\
\hline
\end{tabular}

passo que o mais difícil nos limiares $b_{1}$ e $b_{2}$ foi o 8, e para o limiar $b_{3}$ e $b_{4}$ o mais difícil foi o item 11. Para a subescala Emoções/Cognições Negativas, a discriminação média do conjunto de itens foi de 1.62 ( $D P=.64)$, indo de .99 (Item 1) a 2.94 (Item 17). Para os limiares $b_{1}, b_{2}$ e $b_{3}$, o item que demandou menor nível de traço latente para ser endossado foi o 3, ao passo que para o limiar $\mathrm{b}_{4} \mathrm{o}$ item mais fácil foi o 17. Já o item mais difícil nos limiares $\mathrm{b}_{1}$ a $\mathrm{b}_{4}$ foi $\mathrm{o} 18$. Os itens relativos à Direção de Risco tiveram discriminação média de $1.42(D P=.56)$, variando de .69 (item 28$)$ a 2.28 (item 25). Referente à dificuldade, para os limiares $b_{1}, b_{2}$ e $b_{3}$ os itens mais fáceis foram o 10 ,
20 e 25 respectivamente, contudo, para o limiar $b_{4}$ o item que exigiu menor quantidade de traço latente para ser completamente endossado foi o 25 . Por outro lado, nos limiares $b_{1}$ e $b_{2} o$ item que exigiu maior traço latente foi o 24. Para os limiares $b_{3}$ e $b_{4}$, o item mais difícil de ser endossado foi o 28.

Por meio de uma Análise Fatorial Confirmatória (estimador WLSMV), utilizando-se a amostra $\mathrm{N}_{2}$, verificaram-se indicadores de ajuste do modelo reduzido proposto, de 15 itens (DDDI 15 ), aos dados. Os resultados indicaram ser plausível pensar na estrutura formada por três fatores da versão reduzida $\mathrm{DDDI}_{15}[\mathrm{CFI}=.99 ; \mathrm{TLI}=.98 \mathrm{e}$ 
Quadro 2. Discriminação e dificuldade dos itens $\left(\mathrm{N}_{1}=220\right)$ e cargas fatoriais $\left(\mathrm{N}_{2}=220\right)$

\begin{tabular}{|c|c|c|c|c|c|c|}
\hline \multirow{2}{*}{ Subescalas/ Itens } & \multicolumn{5}{|c|}{$\mathrm{N}_{1}$} & \multirow{2}{*}{$\frac{\mathrm{N}_{2}}{\lambda}$} \\
\hline & $\mathrm{a}$ & b1 & b2 & b3 & b4 & \\
\hline Direção Agressiva & ---- & ---- & ---- & ---- & ---- & ---- \\
\hline i05* & 3.400 & .578 & 1.339 & 2.159 & 3.146 & .50 \\
\hline i06* & 2.853 & .160 & .993 & 1.851 & 2.414 & .62 \\
\hline $\mathrm{i} 07 *$ & 1.236 & 1.345 & 2.236 & 3.191 & 3.824 & .38 \\
\hline i08* & 1.531 & 1.526 & 2.284 & 3.309 & 4.358 & .30 \\
\hline i11* & .928 & .172 & 2.193 & 4.119 & 6.138 & .56 \\
\hline i16 & 1.091 & .445 & 1.884 & 3.434 & 4.798 & ---- \\
\hline Emoções/Cognições Negativas & ---- & ---- & ---- & ---- & ---- & ---- \\
\hline $\mathrm{i} 17 *$ & 2.937 & -1.479 & -.242 & .719 & 1.480 & .72 \\
\hline i19* & 1.774 & -1.697 & -.165 & 1.050 & 1.880 & .51 \\
\hline $\mathrm{i} 02 *$ & 1.617 & -1.316 & .549 & 1.887 & 3.147 & .66 \\
\hline i12* & 1.409 & -1.987 & -.129 & 1.348 & 2.445 & .71 \\
\hline i18* & 1.408 & .162 & 1.700 & 2.670 & 3.958 & .67 \\
\hline i03 & 1.194 & -3.590 & -1.634 & .368 & 2.385 & --- \\
\hline i01 & .986 & -2.364 & -.447 & 1.982 & 3.553 & --- \\
\hline Direção de Risco & ---- & ---- & ---- & ---- & ---- & ---- \\
\hline $\mathrm{i} 25^{*}$ & 2.284 & .562 & 1.160 & 1.934 & 2.569 & .30 \\
\hline i $27 *$ & 2.235 & -.202 & 1.277 & 2.149 & 3.334 & .57 \\
\hline i20* & 1.570 & -.063 & 1.128 & 2.149 & 2.705 & .62 \\
\hline i23* & 1.519 & 1.274 & 2.245 & 3.704 & 4.186 & .33 \\
\hline i15* & 1.501 & .325 & 1.614 & 2.478 & 3.083 & .40 \\
\hline i10 & 1.154 & -.250 & 1.608 & 2.831 & 3.751 & ---- \\
\hline i13 & .991 & 1.607 & 2.580 & 3.279 & 4.683 & ---- \\
\hline i24 & .880 & 2.030 & 3.680 & 4.232 & 5.212 & ---- \\
\hline i28 & .691 & .469 & 2.555 & 4.765 & 7.022 & ---- \\
\hline
\end{tabular}

RMSEA (IC90\%)=.03 (.00-.05)]. Os valores dos Lambdas $(\lambda)$ padronizados podem ser vistos no Quadro 2, sendo todos estatisticamente significativos e diferentes de zero $(\lambda \neq 0 ; \mathrm{z}>1.96$, $p<.05)$, com valor médio de $.52 \quad(D P=.15)$, variando de .30 (Item 25 e 08) a .72 (Item 17). Ademais, observaram-se as seguintes correlações entre os fatores: Direção de Risco e Emoções/Cognições Negativas $(r=.76, p<.01)$, Direção de Risco e Direção Agressiva ( $r=.60$, $p<.01)$ e Emoções/Cognições Negativas e Direção Agressiva $(r=.71, p<.01)$. No que se refere à precisão, os indicadores são aceitáveis, encontrando os seguintes valores: fator Direção Agressiva $(\omega=.62 ; \mathrm{CC}=.60)$, Emoções/Cognições Negativas $(\omega=.80 ; \mathrm{CC}=.79)$ e Direção de Risco $(\omega=.60 ; \mathrm{CC}=.56)$, além de apresentar um $\omega=.84$ quando se considera os 15 itens.

\section{Validade Concorrente}

Por fim, tendo em conta todos os participantes $\left(\mathrm{N}_{\mathrm{T}}=440\right)$, verificou-se o padrão de correlações que a versão reduzida da DDDI, composta por 15 itens, estabelece com a pontuação total da Escala de Infrações de Trânsito, e com o autorrelato sobre a frequência de envolvimento em acidentes, o número de multas recebidas e a participação em brigas no trânsito (Quadro 3). A pontuação total da versão reduzida da DDDI se correlacionou positivamente com a pontuação total da escala de infrações no trânsito $(r=.52, p<.01)$, com o número de acidentes sofridos $(r=.14, p<.01)$ e com o envolvimento em brigas no trânsito $(r=.20$, $p<.01)$. As subescalas da DDDI, formadas por cinco itens cada, correlacionaram-se positivamente com a escala de infrações no trânsito $(r=.50, p<.01 \mathrm{com}$ Direção de Risco; $r=.36, \quad p<.01 \quad$ com Direção Agressiva; e $r=.39, p<.01$ com Emoções/Cognições Negativas). Especificamente, Direção de Risco se correlacionou positivamente com o envolvimento em acidentes $(r=.14, p<.01)$. Direção Agressiva o fez na mesma direção com o número de acidentes sofridos $(r=.15, p<.01)$ e com o envolvimento em brigas de trânsito ( $r=.26, p<.01)$. Emoções/Cognições Negativas se correlacionou positivamente com o envolvimento em brigas no trânsito $(r=.18, p<.01)$.

Quadro 3. Correlatos da DDDI

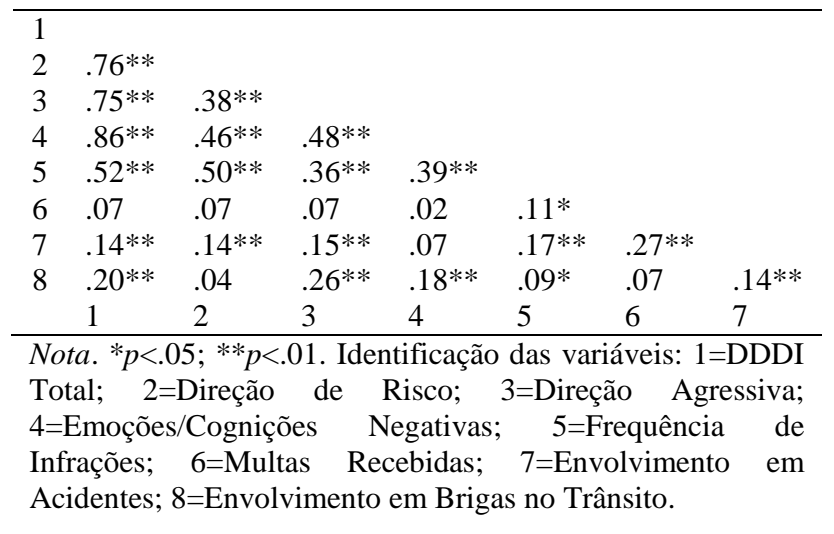




\section{Discussão}

O trânsito brasileiro é um dos mais violentos da América (WHO, 2015), apesar das diversas ações propostas para diminuição do número de acidentes (Bacchieri \& Barros, 2011). As ações têm se pautado muito mais em punir do que em educar os motoristas e propor ações interventivas para grupos propensos a envolver-se em acidentes. Ademais, no Brasil poucos são os estudos que buscam conhecer variáveis relacionadas a comportamentos imprudentes no trânsito. Talvez o reduzido número de estudos se deva a carência de instrumentos que mensurem as diferenças individuais para dirigir perigosamente. Nesta direção, o presente artigo objetivou explorar os parâmetros psicométricos da Dula Dangerous Driving Index no Brasil.

Estima-se que os propósitos do estudo foram alcançados. Por meio da Análise Paralela, com suporte da Modelagem por equações estruturais exploratória, identificou-se uma estrutura formada por três fatores, sendo excluídos cinco itens por não pertencerem teoricamente aos fatores e um por apresentar carga fatorial abaixo do recomendado pela literatura (|.30|; Pasquali, 2012), resultando em uma versão de 22 itens. No que tange à fidedignidade, foram observados coeficientes de consistência interna aceitáveis, estimados por meio do ômega de McDonald e Confiabilidade Composta. Portanto, a versão da DDDI formada por 22 itens reuniu evidências favoráveis de validade e precisão, replicando-se no Brasil a estrutura observada em estudos prévios (Dula \& Ballard, 2003; Dula \& Geller, 2003; Richer \& Bergeron, 2012). Logo, parece plausível compreender a tendência para dirigir perigosamente como um construto formado por tendências a agir de forma agressiva com outros motoristas, além de instabilidade emocional no trânsito e uma propensão para correr riscos ao dirigir (Dula \& Geller, 2003).

$\mathrm{Na}$ literatura científica da área não foi possível encontrar estudos que avaliaram a DDDI por meio da TRI, sendo esta a primeira contribuição. Todos os itens tiveram discriminação entre moderada e muito elevada (Baker, 2001) e dificuldades variadas. Inspecionando as dificuldades dos itens e as curvas de informação, percebe-se que as dimensões mais severas do comportamento perigoso ao volante são a Direção de Risco (DR) e Direção Agressiva (DA). Estes fatores avaliaram com maior acurácia pessoas na faixa moderada e elevada de traço latente. Por outro lado, Emoções/Cognições Negativas (ECN) são elementos da direção perigosa mais presentes entre os motoristas avaliados, pois no geral seus itens são mais fáceis de serem endossados e a escala se mostrou informativa para pessoas com baixo, moderado e elevado traço latente.

Com base em tais resultados, é fundamental pensar em ações preventivas que busquem reduzir a irritabilidade, raiva, frustração e outros aspectos relacionados a emoções negativas. Estas se correlacionaram com número de infrações cometidas e envolvimento em brigas no trânsito no presente estudo, além de outras evidências na literatura indicarem relações deste componente com erros, lapsos e violações no trânsito $(\mathrm{Qu}$ et al., 2014). Logo, é fundamental pensar em ações propositivas que aumentem a capacidade das pessoas em gerenciar suas emoções enquanto dirigem, algo que pode reduzir comportamentos imprudentes no trânsito (Ge et al., 2014).

No que tange a versão concisa da DDDI, alternativa que pode facilitar o emprego da medida em pesquisas com múltiplas variáveis ou em contextos que demandam rápida aplicação, selecionaram-se 15 itens com base em seus parâmetros individuais. Esta versão foi submetida a uma $\mathrm{AFC}$ (estimador não paramétrico), apresentando, no conjunto, índices que apontam um ajuste adequado do modelo aos dados (CFI=.99; TLI=.98; RMSEA=.03; Brown, 2006; Kline, 2016), reunindo-se evidências adicionais em torno da estrutura de três fatores, assim como verificado em pesquisas prévias (Ge et al., 2014; Iliescu \& Sârbescu, 2013).

A validade concorrente desta versão reduzida foi aferida com base nas correlações positivas entre a pontuação total da DDDI e seus fatores com infrações de trânsito, DR com envolvimento em acidentes, DA com envolvimento em acidentes e brigas no trânsito e ECN com esta última, congruente com achados prévios (Richer \& Bergeron, 2012; Qu et al., 2014; Wu et al., 2014). A partir do exposto, reuniram-se evidências em torno da validade fatorial e concorrente da DDDI, assegurando a consistência 
interna dos seus fatores, e a qualidade individual de seus itens. Apesar das contribuições do presente estudo, é importante citar potenciais limitações. Uma delas se refere a natureza da amostra, do tipo não probabilística, impossibilitando a generalização dos resultados. Outra limitação se refere a coleta de informações referentes a multas recebidas, infrações cometidas, envolvimento em acidentes e brigas. No caso, confiou-se unicamente no autorrelato dos participantes, sendo que esse tipo de informação pode não ter sido relatado com precisão.

Em possibilidades futuras cabe coletar informações com amostras maiores e mais heterogêneas, se utilizar de observações naturalísticas ou em ambientes controlados tendo em conta o comportamento das pessoas em simuladores, relacionando os erros à DDDI. De igual relevância seria conhecer os antecedentes do comportamento de risco ao volante, tanto os psicológicos (traços de personalidade, ansiedade e estresse) quanto os situacionais (motorização e tipo de carro), testando o potencial papel moderador de variáveis demográficas, como o sexo e a idade, que são apontados na literatura como importantes preditores.

\section{Referências}

Alchieri, J. C., \& Stroher, F. (2003). Características do processo de avaliação psicológica para conductores de veículos: um estudo sobre a tomada de decisão dos psicólogos na utilização de testes psicológicos no Brasil. Revista Iberoamericana de Diagnóstico y Evaluación Psicológica, 15, 107-119.

Baker, F.B. (2001). The basics of item response theory. Washington, DC: ERIC Clearinghouse on Assessment and Evaluation.

Bacchieri, G., \& Barros, A. J. D. (2011). Acidentes de trânsito no Brasil de 1998 a 2010: Muitas mudanças e poucos resultados. Revista de Saúde Pública, 45, 949$63 . \quad$ http://dx.doi.org/10.1590/S003489102011005000069.

Brown, T. A. (2006). Confirmatory factor analysis for applied research. New York: The Guilford Press.
Chalmers, R. P. (2012). MIRT: A multidimensional item response theory package for the $\mathrm{R}$ environment. Journal of Statistical Software, 48, 1-29. Retirado de https://www.jstatsoft.org/article/view/v048i06

DATASUS (2014). Óbitos por causas externas. Retirado de http://tabnet.datasus.gov.br/cgi/tabcgi.exe?sim /cnv/ext10uf.def

Dula, C. S., Adams, C. L., Miesner, M. T., \& Leonard, R. L. (2010). Examining relationships between anxiety and dangerous driving. Accident Analysis \& Prevention, 42(6), 2050-2056. http://dx.doi.org/10.1016/j.aap.2010.06.016

Dula, C. S., \& Ballard, M. E. (2003). Development and evaluation of a measure of dangerous, aggressive, negative emotional, and risky driving. Journal of Applied Social Psychology, 33, 263-282. http://dx.doi.org/10.1111/j.1559-

1816.2003.tb01896.x

Dula, C. S., \& Geller, E. S. (2003). Risky, aggressive, or emotional driving: Addressing the need for consistent communication in research. Journal of safety research,34(5), 559-566.

https://doi.org/10.1016/j.jsr.2003.03.004

Ferreira, I. S., Maurício, A. P., Simões, M. R. (2013). Avaliação psicológica de condutores idosos em Portugal: Legislação e linhas de orientação prática. Revista Iberoamericana de Diagnóstico y Evaluaciòn Psicològica, 35, 201-223. Retirado de http://www.aidep.org/03_ridep/r35/r35art10.p df

Ge, Y., Qu, W., Jiang, C., Du, F., Sun, X., \& Zhang, K. (2014). The effect of stress and personality on dangerous driving behavior among Chinese drivers. Accident Analysis \& Prevention, 73, 34-40. https://doi.org/10.1016/j.aap.2014.07.024

Hayton, J. C., Allen, D. G., \& Scarpello, V. (2004). Factor retention decisions in exploratory factor analysis: A tutorial on parallel analysis. Organizational Research Methods, 7, 191-205. https://doi.org/10.1177/1094428104263675

Iliescu, D., \& Sârbescu, P. (2013). The relationship of dangerous driving with traffic 
offenses: A study on an adapted measure of dangerous driving. Accident Analysis \& Prevention, 51, 33-41. https://doi.org/10.1016/j.aap.2012.10.014

Kline, R. B. (2016). Principles and practice of structural equation modeling (4th ed.). New York: Guilford Press.

Pasquali, L. (2012). Análise fatorial para pesquisadores. Brasília, DF: LabPam.

R Development Core Team. (2015). R: A language and environment for statistical computing. Retrieved from: https://cran.rproject.org/doc/manuals/fullrefman.pdf

Richer, I., \& Bergeron, J. (2012). Differentiating risky and aggressive driving: Further support of the internal validity of the Dula Dangerous Driving Index. Accident Analysis \& Prevention, 45, 620-627. https://doi.org/10.1016/j.aap.2011.09.014

Samejima, F. (1969). Estimation of latent ability using a response pattern of graded scores. Psychometrika Monograph Supplement No. 17. Richmond, VA: Psychometric Society.

Qu, W., Ge, Y., Jiang, C., Du, F., \& Zhang, K. (2014). The Dula Dangerous Driving Index in China: an investigation of reliability and validity. Accident Analysis \& Prevention, 64, 62-68. https://doi.org/10.1016/j.aap.2013.11.004

Willemsen, J., Dula, C. S., Declercq, F., \& Verhaeghe, P. (2008). The Dula Dangerous Driving Index: An investigation of reliability and validity across cultures. Accident Analysis \& Prevention, 40, 798-806. https://doi.org/10.1016/j.aap.2007.09.019

Wit, P. A. J. M., Souza, C. Z., \& Cruz, R. M. (2016). Improving accident statistics and expanding the role of traffic psychologists in Brazil. Psicologia: Ciência e Profissão, 36, 816-830. $\quad$ http://dx.doi.org/10.1590/19823703002382016

World Health Organization (2015). Global status report on road safety 2015. World Health Organization: Genebra.

Wu, K. F., Aguero-Valverde, J., \& Jovanis, P. P. (2014). Using naturalistic driving data to explore the association between traffic safetyrelated events and crash risk at driver level. Accident Analysis \& Prevention, 72, 210-218. http://dx.doi.org/doi: 10.1016/j.aap.2014.07.005. 